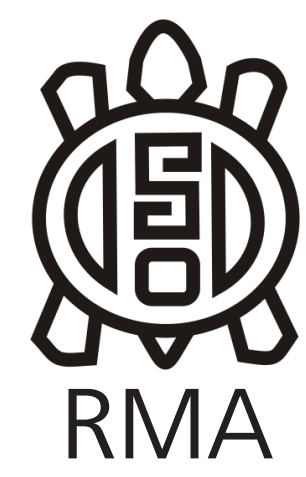

Museología

\title{
Wanda Hanke y la recopilación de información y colecciones antropológicas (1934-1944)
}

\author{
Wanda Hanke and the compilation of anthropological information and \\ collections (1934-1944) \\ Ana Carolina Arias
}

Archivo Histórico del Museo de La Plata, Facultad de Ciencias Naturales y Museo, UNLP, Argentina. E-mail: anacarolinaarias@yahoo.com.ar

\begin{abstract}
Resumen
Este trabajo se concentra en las prácticas científicas vinculadas a la formación de colecciones, considerando su articulación con distintas prácticas comerciales, la recolección de los objetos en "el campo" y el papel de diferentes individuos que intervienen en la obtención y recopilación de los objetos. Para examinar estas cuestiones, se analizan las publicaciones y la documentación de la médica y exploradora austriaca Wanda Hanke. Sus actividades son comprendidas en un contexto de expansión de los museos en diferentes ciudades y provincias en las décadas de 1930 y 1940. El análisis permite comparar sus prácticas con las de aquellos personajes itinerantes que desde el siglo XIX recorrieron el continente sudamericano adoptando la identidad de explorador, pero también desarrollando prácticas ligadas a la medicina, el periodismo y el mercado del coleccionismo, articulando actividades científicas y mercantiles alrededor del conocimiento y de los objetos de pueblos indígenas.
\end{abstract}

Palabras claves: Museo; colección antropológica; Wanda Hanke

\begin{abstract}
This work concentrates on the scientific practices related to formation of collections, considering its articulation with different commercial practices, the compilation of objects in "the field" and the role of different individuals who take part in the collecting and compilation of the objects. To examine these questions, are analyzed publications and papers of austrian physician and explorer Wanda Hanke. Its activities are understood in a context of expansion of the museums in different cities and provinces in the decades of 1930 and 1940. The analysis allows to compare its practices with those of itinerant characters who from the 19th century toured the South American continent adopting the explorer's identity, also developing practices tied to medicine, journalism and market of collecting, coordinating scientific and commercial activities around the knowledge and objects of indigenous peoples.
\end{abstract}

Keywords: Museum; Anthropological collection; Wanda Hanke

Los estudios sobre museos y sobre el proceso de formación de colecciones han tenido un desarrollo creciente en las últimas décadas, con diferentes enfoques e intereses, entre los que se encuentra el estudio de la historia de las "ciencias del terreno", el cual es adoptado en este trabajo. En los últimos años, la historiografía sobre museos de historia natural ha ampliado su mirada hacia las prácticas asociadas a la colección de objetos etnográficos y antropológicos y sobre las relaciones que median entre el campo, el gabinete y los poseedores de un conocimiento local sobre las cosas; considerando también las formas de ordenar estos materiales y ubicarlos en un lenguaje universal (Kuklick y Kohler, 1996; Penny 2002). Como señalan Podgorny y Lopes (2013), desde mediados de 1980 la historia de estas instituciones comenzó a comprenderse a partir de un mundo de dimensiones que exceden las salas de exhibición y los depósitos. Esta nueva mirada sobre los museos remite a un conjunto de cuestiones, tales como las redes de intercambio y de provisión de datos y artefactos que se tendieron entre los científicos y las administraciones de los mismos; proponiendo apartarse de las historiografías tradicionales, centradas en las figuras fundadoras y sus voluntades personales (Podgorny y Lopes 2013).

En cuanto a las prácticas de coleccionismo, Penny muestra cómo desde el siglo XIX se establece una conexión entre posesión y conocimiento que lleva a los etnólogos a concentrar sus esfuerzos en la localización y adquisición de objetos etnográficos, priorizando esta actividad por sobre otras, como la clasificación y el ordenamiento de las colecciones. Las adquisiciones, en este marco, pasaron de ser un sentido a una finalidad y se enfocaron en aquellas áreas donde no hubieron recolecciones, y donde las culturas que producen los objetos aparentaban estar desapareciendo, o donde los objetos etnográficos fueran difíciles de obtener. (Penny, 2002:53). Si bien su análisis se dedica a los museos alemanes en el siglo XIX, estas prácticas fueron comunes a los museos en una escala internacional. En 
el siglo $X X$, muchas de estas prácticas aún persisten y el coleccionismo -y el mercado alrededor del mismocontinúa siendo parte del funcionamiento cotidiano de los museos. En línea con estas ideas, se han generado un conjunto de trabajos sobre los museos argentinos, donde se señala cómo utilizaron diferentes estrategias para la formación de sus colecciones; integrando redes -nacionales e internacionales- de intercambio de objetos y estableciendo redes de recolectores en diferentes territorios (Podgorny y Lopes, 2008; Farro, 2009). Estas redes funcionaron mediante instrucciones enviadas desde los museos y solicitando la colaboración de distintos miembros del gobierno nacional y provincial, de funcionarios escolares, profesores y coleccionistas particulares, entre otros. También se organizaron expediciones oficiales desde los museos, se estimularon las donaciones de particulares, se nombraron "corresponsales" en el campo y se compraron objetos a coleccionistas y a comerciantes de especímenes de historia natural, de objetos etnográficos y arqueológicos (Pegoraro, 2003, 2009; García 2007, 2011; Pupio, 2011).

Siguiendo estas líneas de investigaciones, en este trabajo se analiza la formación de colecciones y la recopilación de información etnográfica durante las décadas de 1930 y 1940 en la Argentina y en algunos países fronterizos, especialmente Paraguay. El objetivo consiste en demostrar la heterogeneidad de las prácticas y los sujetos que se relacionan con las ciencias antropológicas en esos años. En particular, se busca mostrar el papel de diferentes individuos en la formación de las colecciones y en la asignación del significado de los objetos. Junto a ello se analiza la logística y la circulación de los materiales etnográficos y antropológicos y su articulación con distintas prácticas comerciales.

Para examinar estos temas, se analiza la actuación de la médica austríaca Wanda Hanke (1893-1958), devenida en exploradora en sus viajes por Sudamérica desde 1934 hasta su muerte en el interior de Brasil. Sus trabajos son mencionados dentro de los antecedentes de las investigaciones etnográficas y lingüísticas de varios grupos indígenas sudamericanos. Sombrio y Lopes (2011), examinando diversos documentos sobre los vínculos de Hanke con las instituciones brasileñas, mencionan la relevancia de este caso para problematizar la participación de las mujeres en las prácticas científicas y en la formación de colecciones etnográficas en la primera parte del siglo XX. Tal como señalan estas autoras, esto lleva a considerar la circulación de objetos, personas e información y a entender las prácticas científicas como forma de comunicación y comercio.

En particular, en este trabajo se examinan las publicaciones y los relatos de los primeros viajes de Hanke por los territorios sudamericanos y las cartas conservadas en los archivos del Museo Etnográfico de

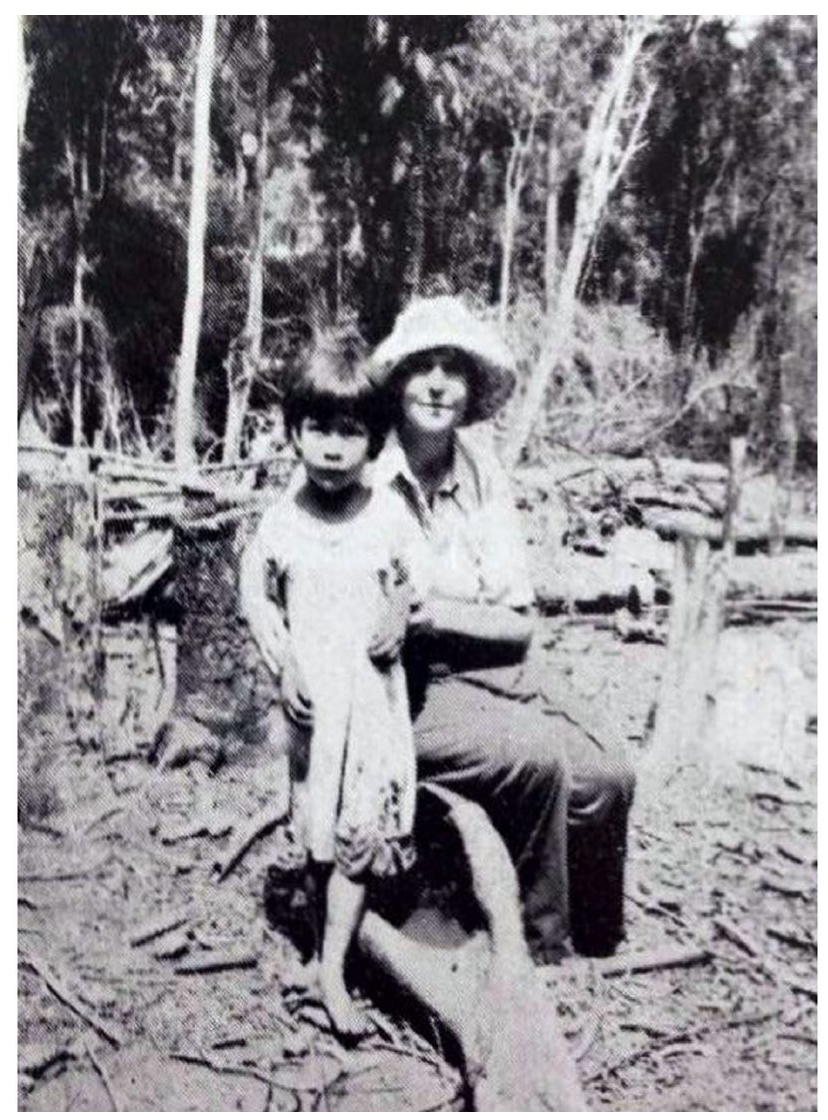

Figura 1: Fotografia publicada en la Revista Geográfica Americana, agosto de 1938. La leyenda original de la foto dice "La autora con Elsita".

Figure 1: Photograph published in the American Geographic Magazine, August, 1938. The original legend of the photo says "The author with Elsita."

Buenos Aires y el Museo de La Plata, instituciones a las cuales ofreció diversas colecciones en venta entre los años 1934 y 1944. Estos documentos permiten indagar en torno a las prácticas comerciales ligadas a la formación de colecciones etnográficas y a las interacciones con miembros de diferentes comunidades y regiones ${ }^{1}$. Por otra parte, las fuentes analizadas muestran los problemas suscitados en la recopilación de objetos e información y en el manejo de las lenguas indígenas, los escenarios de los contactos y de los intercambios a los que éstos daban lugar.

Las prácticas que se analizan en este trabajo deben ser entendidas en un contexto de expansión de los museos en diferentes ciudades y provincias en las décadas de 1930 y 1940, en general museos locales y regionales, algunos vinculados a espacios universitarios y estatales, otros originados a partir de colecciones de museos

\footnotetext{
Las regiones y comunidades que visita Hanke son innumerables, a modo de ejemplificar, se pueden mencionar algunos grupos con los cuales establece contacto (utilizando su terminología): Ashluslays, Botocudos, Cainguá, Guaraníes, Guayaquíes, Lenguas (del norte y del Sud), Matacos, Carijos, Chacaes, Chiriguanos, Coroados, Guarayos, Macaes, Mbyaes, Pilagá, Sanapaná, Siriono, Tereno, Cadivens, Tobas, entre otros. Liener (2010) proporciona una lista de procedencia de todas las colecciones reunidas por Hanke.
} 
escolares (García, 2011). Muchas de estas instituciones tuvieron su origen en las figuras de coleccionistas y amateurs que cedieron o vendieron sus colecciones privadas. Así sucede, por ejemplo, con la colección arqueológica de Enrique Amadeo Artayeta, que fue comprada por el Estado nacional para conformar la base del Museo de la Patagonia en 1939 (Pupio y Piantoni, 2016). En estos años también se conforman las colecciones que serán la "base" del futuro Museo Antropológico de la Universidad de Córdoba, en el marco del Instituto de Arqueología, Lingüística y Folklore, impulsadas desde la gestión en la dirección de Antonio Serrano para el período 1941-1948. Serrano establecerá ciertos modos de formar las colecciones, recurriendo principalmente a sus redes de contactos previos -especialmente maestros de escuelas de distintas regiones-; y sumando también los materiales obtenidos en sus proyectos de investigación. Con estas estrategias, Serrano logra integrar una colección de objetos arqueológicos, folklóricos y etnográficos que le permite inaugurar oficialmente las actividades del Instituto en octubre de 1942 (Bonnin, 2011). Por estos años también, Emilio Wagner en Santiago del Estero estaba al frente del Museo Arcaico, formado en 1916 a partir de la donación de la colección particular del intendente Alejandro Gancedo (h). Emilio y su hermano Duncan desarrollaron numerosas excavaciones arqueológicas en la región y sus hallazgos e interpretaciones generaron ciertos conflictos en el campo arqueológico nacional (Martínez, Taboada y Auat, 2011). A pesar de ello, los materiales arqueológicos trabajados por los hermanos Wagner alcanzaron una gran difusión en el país y entre especialistas extranjeros, incorporándose como parte de la representación de la provincia (García, 2011).

Por su parte, Pupio (2011), al analizar las prácticas amateurs en la provincia de Buenos Aires, señala que hacia mediados de siglo $\mathrm{XX}$ :

"los datos ofrecidos por coleccionistas y aficionados configuraban una suerte de mapa arqueológico del cual se servían los profesionales para conocer nuevas áreas, para confirmar datos o para continuar el trabajo en un yacimiento determinado. En este sentido la comunicación con los lugareños fue parte de la práctica de la arqueología, que permitía obtener datos de campo en un contexto donde las exploraciones científicas subsidiadas por las instituciones no alcanzaban a cubrir las necesidades de información. Por otro lado eran pocos los profesionales dedicados a la arqueología en el país." (Pupio, 2011: 273)

De esta forma, se conformaba un conjunto de relaciones extra académicas, que permitieron conformar un "ejército de aficionados" (Podgorny 2009), para el cual se establecieron diferentes redes de relaciones más o menos recíprocas. También por esos años hubo coleccionistas y científicos que realizaban diversas prácticas y que con menor o mayor éxito buscaron insertarse en puestos estables en diferentes instituciones. Como ejemplo, se puede mencionar al alemán Jorge von Hauenschild quien estableció un museo privado en Santiago del Estero y luego de varias negociaciones, consigue vender su colección a la Universidad de Córdoba, obteniendo un cargo en la misma (Lindskoug 2008).

\section{De médica a exploradora}

Wanda Theressia Leokadia Hanke nació el 9 de diciembre de 1893 en Troppau (población de la actual República Checa), por entonces parte del Imperio Austrohúngaro. En 1918, se doctoró en Filosofía en la Universidad de Munich. Dos años después, terminó los estudios de medicina en Wurzburgo y en 1926, los de abogacía en Marburgo. Trabajó como médica en Alemania y Austria hasta que decidió hacer un viaje de estudio etnológico. A los cuarenta años dejó sus actividades en Viena y a su hijo con su madre, para embarcarse hacia Sudamérica y estudiar los grupos indígenas de la floresta. Según Liener (2010), quien ha trabajado con archivos institucionales y familiares, Hanke había estado internada en diferentes hospitales austriacos y alemanes por problemas psíquicos y es posible que la partida hacia Sudamérica estuviera motivada por el miedo a ser sometida a otra internación. Sin embargo, esta autora considera que no son del todo claros los motivos por los cuales esta médica dejó sus ocupaciones y familia para dedicarse a la exploración, a la formación de colecciones y al registro de las lenguas indígenas.

En 1933 Hanke solicitó permiso para realizar una exploración por el interior del Brasil al recién creado Consejo de Fiscalización de Expediciones Artísticas y Científicas de Brasil ${ }^{2}$, el cual no le fue concedido ${ }^{3}$. Según Sombrio (2014) los "síntomas de anormalidad mental" de Hanke fueron parte de los argumentos para rechazar su solicitud y negarle la licencia para realizar expediciones en Brasil. En septiembre de 1940, Hanke eleva un nuevo pedido al Consejo, que volvió a ser rechazado, esta vez, por no cumplir con la normativa que exigía la intermediación del Ministerio de Relaciones Exteriores. Si bien ambas negativas de este Consejo implicaron algunas dificultades para Hanke, no le impiden realizar expediciones y juntar materiales en ese país, incluso contando con la ayuda de otras reparticiones estatales

\footnotetext{
${ }^{2}$ El Consejo funcionó entre 1933 y 1968 y se ocupaba de controlar y fiscalizar las expediciones realizadas por extranjeros y particulares (sin vínculos a instituciones científicas) por los territorios de Brasil. Sobre la historia de este organismo véase: Grupioni (1998). Por su parte, Sombrio (2014) analiza la documentación de este organismo para detectar la presencia de mujeres expedicionarias y analizar sus trayectorias, considerando especialmente sus actividades vinculadas al trabajo de campo a mediados de siglo XX.

${ }^{3}$ El viaje tenía la intención de realizar una expedición en las regiones desconocidas de los ríos Xingu, Tapajós y sus afluentes, en compañía de un etnólogo y un geógrafo y según la carta de Hanke contaba con el financiamiento de la Fundación Rockefeller (Sombrio 2014: 161).
} 
como el Servicio de Protección a los Indios o del ejército, que tenían más presencia en el territorio que el Consejo de Fiscalización de Expediciones Artísticas y Científicas (Sombrio, 2014).

Aunque en 1933, Hanke no obtuvo el permiso de las autoridades brasileñas, igual decidió viajar a Sudamérica aunque cambiando el itinerario. En agosto de 1934, desembarcó en Buenos Aires, donde permaneció un mes aprendiendo los rudimentos del español, para luego dirigirse al territorio de Misiones. También visitó la región chaqueña de Paraguay. En 1936 retorna a Buenos Aires, ofreciendo conferencias en la unión germánica sobre los indios que visitó. Ese año viaja a Viena donde permanece unos meses y en septiembre de 1937 regresa a América del Sur, para quedarse en este hemisferio durante 18 años, recorriendo parte del Noroeste y Noreste argentino, Paraguay, Bolivia y Brasil. Entre 1952 y 1955 trabaja en la Universidad Mayor de San Simón de Cochabamba, Bolivia (Ocampo Moscoso 1982). En 1955 regresa a Europa, pasando por España e Italia antes de llegar a Austria y Alemania en diciembre de 1956. En 1957 vuelve a Brasil, donde continúa realizando exploraciones hasta su muerte, el 30 de agosto de 1958 en Benjamin Constant, Amazonas. Sus viajes a Europa los aprovecharía para vender colecciones, dar conferencias y recaudar dinero para nuevos recorridos e investigaciones ${ }^{4}$. Hasta su muerte, realizó numerosas exploraciones y observaciones sobre distintos grupos indígenas de Misiones y el Chaco argentino, Paraguay, las tierras bajas de Bolivia y el interior de Brasil, recopilando dialectos, mitos, dibujos, fotografías y colecciones que ofrecería en venta a museos de varios países.

La forma de trasladarse, los trabajos y los recursos de Hanke varían a lo largo de los veinticuatro años que recorre América del Sur. En este artículo solo se profundiza en sus primeros años en el territorio sudamericano a través de la correspondencia que mantuvo con antropólogos y otros científicos de la Argentina. Hanke establece vínculos con diferentes instituciones de los países de la región, actuando como mediadora entre las mismas y "el campo". Con el tiempo y la suma de experiencias exitosas y fallidas, perfecciona sus habilidades comerciales y científicas ${ }^{5}$. A medida

\footnotetext{
${ }^{4}$ La mayoría de los objetos ofrecidos por Hanke en Europa fueron adquiridos por el Museo de Etnología de Viena. En dicho museo se registran actualmente 682 objetos coleccionados por Hanke, recibidos en dos períodos en los cuales estuvo en contacto con el museo, entre 1935 y 1938 y entre 1955 y 1957. Esta colección ha sido analizada en profundidad por Liener (2010).

${ }^{5}$ Como ejemplo de sus mejoras científicas, se puede citar su progresivo aprendizaje en el manejo del idioma español en sus publicaciones, notas y correspondencias; así como la búsqueda de espacios más calificados académicamente donde publicar sus trabajos. Asimismo, con el paso de los años se irá orientando a temas más específicos, como el lenguaje y las condiciones de vida de determinados grupos indígenas. Otros ejemplos se mencionan más adelante, por ejemplo, la adecuación de sus envíos -tanto de información como de objetosa los parámetros solicitados por cada institución. Hanke también irá conociendo los temas de interés de cada investigador y recopilando
}

que va moviéndose, establece redes de intercambio de objetos e informaciones, actuando muchas veces en función de los intereses de adquisición de cada museo o de los investigadores con los cuales intercambia correspondencia 6 .

Cabe destacar que Hanke realizó sus diferentes actividades sin contar con un puesto regular en algún museo, situación habitual en la época. Sin embargo, informalmente recibió distintos tipos de ayudas de personas particulares y de los museos con los que se contactaba y se ofrecía como recolectora y/o colaboradora en el "campo". Como se puede observar en la documentación guardada en el Archivo Fotográfico y Documental del Museo Etnográfico de Buenos Aires y en el Archivo Histórico del Museo de La Plata7, esa ayuda podía consistir en el pago de gastos de pasajes, alojamiento, revelado de fotografías, traslado de colecciones. En otras ocasiones, recibiría asistencia para publicar artículos y corregir el español en sus textos. También la ayudarían en contactos con otras instituciones científicas y gubernamentales y el apoyo en las gestiones ante las embajadas de los países vecinos cuando Hanke tuvo algunos problemas por sus actividades, especialmente durante los años de la segunda guerra mundial.

Al igual que otros viajeros y exploradores, Hanke se movió entre los contactos provistos por las redes de connacionales o con los que compartía el mismo idioma materno. En su caso, se vinculó sobre todo con germano-parlantes, tanto colonos como científicos, que le permitieron relacionarse con ciertas instituciones. En el Museo de La Plata, por ejemplo, contará con la ayuda del geólogo alemán Walter Schiller, quien le proveerá contactos con otros científicos alemanes en Bolivia. Asimismo, al iniciarse la segunda guerra mundial se moverá a través del apoyo de las redes consulares, por ejemplo, con la delegación alemana en el territorio de Misiones. En esos años, para trasladar las piezas vendidas a los museos, como en el caso del Museo de La Plata, recurrió a los contactos y el amparo provisto por las delegaciones diplomáticas argentinas en los países vecinos.

Para subvencionar sus viajes y actividades, la exploradora implementa diferentes estrategias. La formación y venta de colecciones etnográficas, junto a algunos objetos arqueológicos y especímenes zoológicos de los sitios visitados constituyen una parte importante de los ingresos de Hanke ${ }^{8}$. Esto se complementa ofreciendo

materiales en función de los mismos.

${ }^{6}$ En Brasil, se contacta principalmente con el director del Museo Paranaense en Curitiba, primero Loureiro Fernandes entre los años 1941 y 1946, y luego Carlos Stellfeld, director hasta 1949 (Sombrio 2014).

${ }^{7}$ En adelante, AFDME y AHMLP respectivamente.

8 Las colecciones y otros objetos de las primeras expediciones de Hanke son adquiridos por diferentes museos, entre ellos el Museo Argentino de Ciencias Naturales "Bernardino Rivadavia", el Museo 
artículos y fotografías a revistas turísticas, de divulgación científica y periódicos. Entre ellos el diario La Prensa, la revista femenina Vosotras y la Revista Geográfica Americana. En esta última publicó dieciséis artículos entre 1937 y 1949, relatando las particularidades de diferentes grupos indígenas y sobre ciertas ciudades, sobre todo aquellas de interés turístico ${ }^{9}$. Además, en esos años, escribió para los Arquivos do Museu Paranaense y para varias publicaciones de lengua germana, como las revistas argentinas Phoenix y Lasso y la alemana Zeitschrift für Ethnologie. También realiza conferencias y publica varios artículos en los organismos de la Sociedad Científica Alemana en la Argentina.

Su diversidad de ocupaciones y estrategias de supervivencia generan dificultades para definir o clasificar su actividad, la cual más bien muestra un panorama de su flexibilidad y perspicacia para encontrar apoyo y financiamiento en sus viajes por regiones poco conocidas de Sudamérica. Sus itinerarios que parecen erráticos y ligados al azar, están sin embargo sostenidos por diferentes redes de contactos, así como de venta de objetos e informaciones que fue estableciendo, muchas veces siguiendo patrones similares.

\section{Intercambios epistolares: favores, negociaciones y aprendizaje}

Uno de los objetivos de Hanke al internarse por primera vez en Sudamérica es estudiar a los "esquivos" Guayaquíes $^{10}$. El 6 de octubre de 1934, llega a la colonia Leandro Alem, en el territorio de Misiones, gracias al servicio de vapores que recorre el Paraná; donde la recibe un amigo austriaco. A partir de allí se dedica a recorrer diferentes territorios y se encuentra con varias colonias y "tolderías" indígenas, en su mayoría del grupo denominado Cainguá. También visita algunos poblados en la costa paraguaya del río Paraná y a principios de 1935 se dirige a la ciudad de Asunción. Mientras se familiariza con la vida en el monte y el lenguaje guaraní, Hanke prepara algunas expediciones para intentar encontrarse con los Guayaquí11.

Este grupo indígena era poco conocido por la ciencia y sus miembros se presentaban como "esquivos"

Etnográfico de la Facultad de Filosofía y Letras de la Universidad de Buenos Aires, el Museo de La Plata, el Museo Paranaense de Curitiba (Brasil) y el Museo Etnológico de Viena (Museum für Völkerkunde).

9 Algunos de los que grupos que describe en esta revista son: Ashluslays, Lenguas, Chacaes, Chiriguanos, Cainguaes, Guayaquies, Macaes, Toba, Pilagá, Guaraníes y "tribus guaranizadas", Guarayos, Mbyaes, Sanapaná, Botocudos y Coroados. También describe ciudades en artículos como "Sierras y Ciudades del Sud de Brasil" (agosto de 1946) y algunas costumbres populares de las regiones visitadas, como la fiesta de la Virgen de Caacupé en Paraguay (octubre de 1946).

${ }^{10} \mathrm{Se}$ toman las denominaciones de los pueblos visitados por Hanke tal cual ella los menciona en sus cartas y publicaciones.

${ }^{11}$ Actualmente, este pueblo se autodenomina aché, considerándose el término "guayaquí" como despectivo ya que significaría "ratón de monte" (Martínez, 2012). Sin embargo, se usa el término Guayaquí por ser el utilizado por Hanke y otros investigadores de la época.

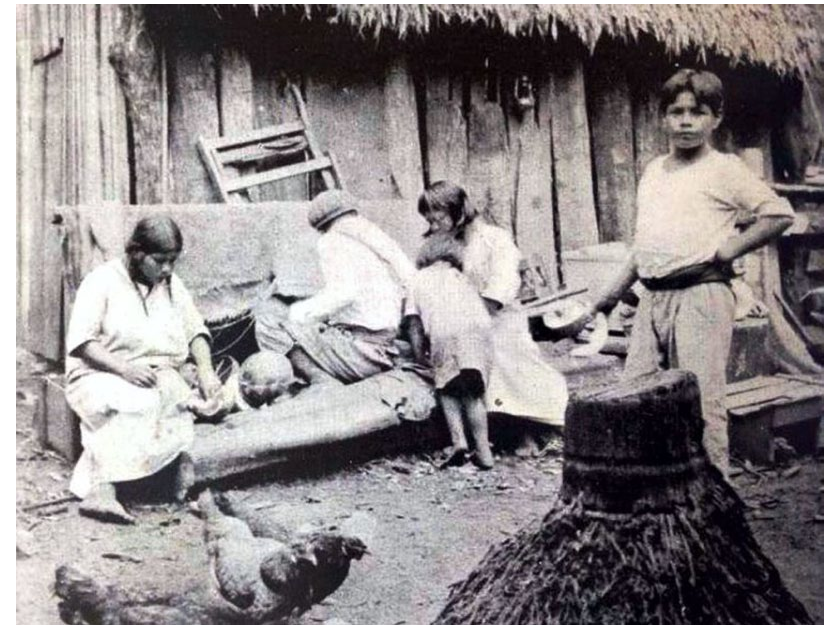

Figura 2: Fotografia publicada en la Revista Geográfica Americana, agosto de 1938. La leyenda original de la foto dice "Una choza Guayaquí con sus enseres y aves domésticas. La familia refrescándose con una sabrosa sandía".

Figure 2: Photograph published in the American Geographic Magazine, August, 1938. The original legend of the photo says "A Guayaqui hut with its utensils and poultry. The family cooling off with a tasty watermelon".

y "hostiles" a la mirada de los antropólogos y exploradores. Como se ha señalado, desde fines de siglo XIX permanecía "casi desconocido aún por aquellas personas que se interesan por la suerte de las razas autóctonas" (La Hitte (1895) en Martínez 2012). A principios de siglo $\mathrm{XX}$, distintos misioneros, científicos $\mathrm{y}$ la prensa local, se habían ocupado de describir y brindar noticias sobre este grupo. En el Congreso Internacional de Americanistas celebrado en Buenos Aires en 1910, el alemán Federico Mayntzhusen presenta una colección particular "guayakí", a raíz de la cual se extiende el interés y las discusiones sobre lo que podría llamarse la "cuestión guayaqui", especialmente en relación a su clasificación lingüística. Este grupo se transformó, según Pegoraro (2009) en un "problema etnográfico" en tanto se consideraba como una tribu interesante por sus rasgos físicos y su cultura material "en estado neolítico" (según Ambrosetti, Vogt y Mayntzhusen) y además porque se cuestionaba la forma en que se había obtenido la información, los datos sobre su lengua, la mezcla de vocablos y otras confusiones relacionadas al difícil contacto directo. Los objetos materiales de los guayaquí eran, por este motivo, considerados como un "testimonio de una sociedad renuente a la civilización" (Pegoraro, 2009: 218). Observarlos y menos aún fotografiarlos en su vida cotidiana no era sencillo, como reconoció el explorador francés Albert-Jehan Vellard (1901-1996), quien entre febrero y octubre de 1932, poco tiempo antes que Hanke, intentó contactarlos (Vellard, 1933). La mayor parte de los objetos e información que obtiene Vellard proviene de "rastros" en la selva y de campamentos abandonados, algo similar a lo que va reunir Hanke dos años después. El francés observa a los Guayaquí a la distancia y desde allí describe algunos comportamientos de su vida cotidiana. Cuando 
intenta un acercamiento, es atacado en su campamento durante la noche y debido a la pérdida de sus baqueanos se retira de la expedición. Algunos datos más sobre este grupo los obtiene de historias que le cuentan los Mbwiha ${ }^{12}$. Hanke, por el contrario, consigue establecer algunos contactos directos, especialmente con algunas mujeres. Esta exploradora publicita ese "logro" en varios artículos, entre ellos, en una nota publicada en $L a$ Prensa el primero de marzo de 1936, donde relata cómo ha logrado contactarlos en las cercanías de Villarica, Paraguay (Hanke, 1936). Para Hanke, quien apenas se iniciaba en el campo de la etnografía, escribir sobre ellos o investigarlos en su "estado natural" adquiría un valor fundamental, tanto para reforzar su carrera científica como para obtener mayores beneficios en la transacción de materiales e informaciones.

En su segundo arribo a Sudamérica, en 1937, Hanke retoma el interés por algunos grupos ya visitados, como los Guayaquíes. Asimismo, recurre a algunas relaciones y correspondencias establecidas en su primer viaje con diferentes investigadores y funcionarios pertenecientes a museos y otras instituciones. Uno de sus intercambios más asiduos fue el realizado con el entonces encargado de la Sección de Antropología del Museo Argentino de Ciencias Naturales "Bernardino Rivadavia", José Imbelloni (1885-1957) ${ }^{13}$, quien la orientó respecto de los materiales y temas de interés del momento, colaborando con sus envíos de materiales a dicho museo así como al Museo Etnográfico de la Universidad de Buenos Aires.

El trato directo con Imbelloni es muy fructífero para Hanke, puesto que actúa como intermediario entre ella y una serie de contactos vinculados a las ciencias antropológicas, a los museos y a la producción cultural. Un buen ejemplo de ello es la relación entre ella y José Anesi $^{14}$, el director de la Revista Geográfica Americana ${ }^{15}$

\footnotetext{
${ }^{12}$ Mediante ciertos "avistamientos" de estos indios, Vellard remarcaba su lugar como uno de los tantos proveedores de datos en la empresa colectiva de observación del mundo y de la naturaleza. Sin embargo, al haber podido observar a pueblo tan esquivo, se destacaba como un recolector más calificado que otros, un reconocimiento que podía traducirse en nuevos encargos y mejores recompensas (Martínez, 2012:14).

${ }^{13}$ El italiano José Imbelloni dirigía esa Sección y era encargado, desde 1922 de las investigaciones antropológicas del Museo Etnográfico de la Facultad de Filosofía y Letras de la Universidad de Buenos Aires, en la cual también se desempeñaba como profesor. Es decir, ocupaba los puestos más importantes en Buenos Aires en el área de Antropología Física.

${ }^{14}$ José Anesi (1881-1963) se había graduado en estudios clásicos y era editor y representante en la Argentina de las más importantes firmas cartográficas italianas, inglesas, francesas y del Instituto Geográfico De Agostini. Poseía una editorial cartográfica desde 1918 y desde 1945 se vinculó a la casa Peuser, quedando asociado a la producción de mapas y atlas.

15 La Revista Geográfica Americana se editó entre 1933 y 1956 con entregas mensuales. Estaba destinada a una amplia audiencia y se financiaba a través de las suscripciones y de la publicidad. En sus páginas se publicaron numerosos trabajos etnográficos y de divulgación de investigaciones científicas, en convivencia con notas orientadas a la promoción del turismo nacional y al conocimiento de la cultura en general (Zusman 2012). José Anesi encabezó la iniciativa
}

donde se publicaron diferentes trabajos de Hanke. Asimismo, Imbelloni recibe los manuscritos de Hanke y los envía a algún ayudante de su área para que los corrija antes ser enviados a la revista. Estos favores permiten sortear algunos problemas de Hanke con el lenguaje español, el cual -como se señala adelante- no manejaba muy hábilmente. Así, las negociaciones que rodean la compra y venta de objetos etnográficos involucran el intercambio de favores.

Los objetos que Hanke ofrece en venta son principalmente etnográficos, son objetos de uso cotidiano para la elaboración y cocción de alimentos, para el transporte, adornos, instrumentos, armas, entre otros. Los envíos a veces contienen también restos óseos humanos y en ocasiones especímenes zoológicos (chanchos de monte, escarabajos, arañas, onza, caracoles, nidos de avispa, entre otros). A esto se suma la recopilación de lenguas, las observaciones realizadas por ella en distintas comunidades, fotografías e ilustraciones realizadas por los indígenas. En algunas tribus realiza mediciones antropométricas (Chiripá, Cainguá, Baticola, Guayaquí). Por lo general envía listados describiendo los materiales (con precios incluidos) y con comentarios acerca de los usos nativos de los objetos y del lugar de procedencia.

Como ejemplo, se transcribe parte de una carta de Wanda Hanke reportando el envío de una caja con materiales obtenidos de los Guayaquíes y de los Cainguás en 1935 al Museo Argentino de Ciencias Naturales que dirigía Martín Doello Jurado, remitiendo también en sus bultos una caja con insectos y muestras de alfarería. La misma se tasaba en el valor total de $25 \$ \mathrm{~m} / \mathrm{n}$ y contenía los siguientes objetos:

- De los indios Cainguá: 1 rebenque, 1 carretel y 1 pipa "de una toldería en el monte atrás de Paso Yobai" obtenidos en febrero de 1935.

- De los indios Guayaquíes: 1 cuchillo y 1 piedra "para abrir las frutas, de un campamento abandonado en el monte", obtenidos a dos leguas de Ñuverá en marzo de 1935; 3 agujas de hueso "de una mujer escapando de nosotros, en el monte, a siete leguas de Ñuverá" obtenidos en marzo de 1935; 1 bandallo, 1 cántaro, 1 cadena de dientes, 1 canasto, estos cuatro "regalados de dos mujeres, con las cuales yo tenía relación en el monte" obtenidos en mayo de 1935.

- Otra colección de los indios Guayaquíes: 1 hacha de piedra, 1 canasto de hilo, 1 soga de cabellos de mujer, 2 huesos de animales "usados de instrumentos". También envía con estos materiales muestras de la tierra que excavó.

Gracias a este intercambio epistolar con Imbelloni y con otros encargados de colecciones o jefes de sección en los museos, Hanke aprende ciertas formas "apropiadas"

de esta revista, que contó con la colaboración de varios naturalistas y antropólogos del país. 
(según los parámetros de los museos) de ofrecer objetos en venta, incorporando los pasos necesarios para vender y enviar las piezas y los datos relevantes que deben ser consignados, como las condiciones de hallazgo y otras descripciones pertinentes al uso $u$ origen de los objetos. En la institución un especialista emitirá su opinión respecto a la tasación de los objetos -en general cuando los mismos son recibidos- en función de su valor científico, luego el valor monetario debe ser aprobado por la dirección y finalmente se le enviará el pago al vendedor. En función de esta tasación experta, Hanke también se irá inclinando a la venta de aquellos objetos que han sido mejor valuados, o dicho de otra manera, aquellos materiales que resultan ser más interesantes para los compradores, los investigadores y responsables de los departamentos específicos del museo. Estos intercambios epistolares permiten apreciar las interacciones y negociaciones colectivas que conforman el valor de los objetos, donde se intercalan apreciaciones científicas y comerciales.

Las formas "apropiadas" de realizar estas transacciones no siempre son respetadas ni tampoco siguen un patrón único. Hanke en diferentes ocasiones intenta vender materiales sin considerar las pautas establecidas por los museos, en algunos casos de forma exitosa. Así sucede con unos esqueletos guayaquíes, que la exploradora asegura que poseen 33 vértebras y que son diferentes a otros esqueletos humanos ${ }^{16}$, como detalla en la siguiente carta a Imbelloni en 1938:

“Ayer escribí una carta al Sr. Doello Jurado pidiéndole dinero y explicándole mi situación. Cerca de aquí hay un lugar donde se encuentran tres esqueletos Guayaquíes. A mí me parece que tienen 33 vértebras y que son diferentes de otros esqueletos humanos. Pero no puedo escavarlos y llevarlos sin ayuda y para ésta tengo que pagar.[...] Excepcionalmente de los 30 pesos de Anesi no recibí ni un centavo desde me fui de Buenos Aires. En Viena me olvidaron completamente aunque mandé ya una gran colección. Lo mismo me pasó en Tucumán. Ni los diarios de Europa ni éstos de Argentina me pagan para mis colaboraciones. Para el museo de Buenos Aires tengo una colección de los Guayaquí y otra de los Chaqueños; la última está en Asunción donde tenía que enseñarla para recibir un préstamo. Yo creo que a Ud. van a interesar mucho los esqueletos de los Guayaqui y por esto le ruego de hablar también de su parte con el Director para que me mande 100 pesos inmediatamente. Después va recibir los esqueletos y objetos de los Guayaquí y puedo yo continuar mis trabajos científicos.

[...] Como ahora con los esqueletos se trata de una ocasión única le pido de ayudarme muy pronto

\footnotetext{
${ }^{16}$ Los seres humanos poseen 33 vértebras durante la etapa fetal y en la niñez, y durante la etapa adulta sólo poseen 24, puesto que los huesos del sacro y el cóccis se unen formando un solo hueso cada uno.
}

\section{hablando con el Director." 17}

Esta carta expresa claramente cómo Hanke expone una serie de argumentos para persuadir a Imbelloni de lo urgente que necesita el dinero, motivándolo para que interfiera en la transacción al asegurar el carácter extraordinario de los esqueletos y el posible valor científico de sus exploraciones en la región. Es curioso que asegura que estos esqueletos tienen 33 vértebras, al mismo tiempo que admite que aún no los ha excavado, solicitando dinero para ello. Su estrategia, sin embargo, es exitosa, puesto que Imbelloni consigue que el Director del Museo, Martín Doello Jurado, compre de forma anticipada la remesa de Hanke, es decir, sin ver los materiales. Imbelloni, aclarará que esto genera una situación excepcional, ya que Doello Jurado adelanta el pago con su propio dinero ${ }^{18}$. Además, Imbelloni le escribe a Hanke recomendando ciertos comportamientos o formas de conducta para las sucesivas transacciones con el museo:

“[...] Debo hacerle resaltar el hecho que dicho envío ha sido una medida absolutamente de excepción, pues el Museo en este momento no tiene sumas disponibles por gastos, y el Director ha tenido que sacarlo de su peculio particular, por el momento. Algo se debe también a mis oficios, habiéndole hecho resaltar que los materiales que Ud.; puede enviar serían de interés para esta sección. Así que sería conveniente que Ud. al acusar recibo de la suma acompañara un agradecimiento personal para el Prof. Doello Jurado. Otra cosa importante, que es oportuno la tenga en cuenta en lo sucesivo, es que el Museo, como toda repartición oficial, no puede de ninguna manera y por ninguna causa hacer entregas de dinero sin haber recibido mercaderías u objetos de colecciones, y este es un particular sobre el cual la contaduría general tiene siempre los ojos bien abiertos. Por eso, cuando Ud. tenga que hacer algún pedido, de carácter pecuniario, en concepto de cesión o venta, tendrá que considerar estas reglamentaciones.

Lo que le he dicho, espero que Ud. entienda, es solo con el afán de ayudarla en esforzada empresa de hacer con la nada lo que pocos se atreverían a hacer con la ayuda pecuniaria de las instituciones. Su estado de necesidad lo comprendo fácilmente aunque espero que ha de recibir ayudas de Viena; ya escribí al Dr. Röck hablándole de la inmensa miseria de sus recursos.

[...] Cuide que los esqueletos de Guayaquí estén completos y cuidadosamente recojidos, teniendo separados los respectivos huesos; enviéme también un croquis del yacimiento y las circunstancias de su identificación. Yo no he hablado con Anesi, pero si

\footnotetext{
17 Enviada desde Puerto Victoria (Misiones, Argentina), el 29 de enero de 1938 a Imbelloni, AFDME.

${ }^{18}$ Esto es una práctica común, puesto que los directores de diferentes museos aseguran la compra cuando no se disponen de más fondos en la partida de gastos, luego recuperan estos gastos en la siguiente ejecución del presupuesto estatal.
} 
tiene algunas fotografías haga un pequeño artículo que se lo corregiremos en el Museo y podremos hacer la tentativa de hacerlo comprar para remitirle su plata. No olvide mantenerse en contacto y enviar lo que cree oportuno, tanto para el Museo como para mí."19

Con el dinero del museo Hanke pudo excavar ${ }^{20}$ y enviar dichos esqueletos a través del vapor de la Compañía "Mihanovich" el 2 de marzo de 1938. Mientras este bulto estaba en camino, Hanke continua la correspondencia con Imbelloni e informa sobre los esqueletos guayaquíes que "todavía tuvieron cabellos y piel y que sin duda eran cadáveres indios". Agrega que vio una vértebra doblada y que los huesos le parecían más chicos que de otra gente y solicita que se le comunique "el valor de un esqueleto, porque quisiera saber si vale la pena escavar más (sic)"21. Poco después, Hanke se interna en el monte e intenta contactar con los "indios", para medirlos y hacerlos dibujar, pensando que eso le interesaría a Imbelloni².

Los siguientes meses, la exploradora envía materiales al museo de los grupos Baticola y Chiripa, fotografías, escritos para la mencionada Revista Geográfica Americana. También remite algunos cajones especiales para Imbelloni conteniendo dibujos indígenas ${ }^{23}$, mates y

\footnotetext{
${ }^{19}$ Carta de Imbelloni a Hanke, enviada desde Buenos Aires el 15 de febrero de 1938.

${ }^{20}$ Por lo general, para las excavaciones Hanke contrata peones. Los suele mencionar brevemente en sus cartas o publicaciones, en el caso de estos esqueletos en particular, dice Hanke: "Son muy importantes para la ciencia no sólo Guayaquí vivos, sino también sus restos óseos. Es difícil encontrar sus esqueletos, y estos hallazgos dependen de circunstancias fortuitas. Aunque tenía referencia de algunos enterratorios Guayaquí. tan sólo pude excavar dos esqueletos, que pertenecen a aquellos indígenas de los que hablé antes y que murieron de una fiebre mortal. Los peones del puerto, temblando de miedo a los espíritus, se rehúsan con energía a enseñar los lugares de entierro. Finalmente hicimos venir a un peón de la colonia, un joven argentino, llamado Paiva, que era menos supersticioso y más inteligente que sus compañeros, el cual nos condujo hasta el sitio, nos ayudó a cavar, cobró y se fue. Las tumbas se encuentran en las barrancas del Río Paraná, un tanto alejadas del puerto. Probablemente el agua, durante las crecientes, arrastró algunos esqueletos, pues en lugar del número que me aseguraron únicamente encontré dos, sin contar los restos muy incompletos de una criaturita de 8 días, víctima de la inhumanidad de su madre. Uno de los esqueletos fue hallado a unos dos metros de profundidad y conservaba aún restos de las partes blandas en putrefacción. El cadáver había sido echado en la fosa cara abajo y cubierto con una lona vieja." (Hanke, 1938: 122).

21 AFDME, carta de Hanke a Imbelloni 6/03/1938

22 Según Carrizo (2014), hacia 1930 la producción de Imbelloni se concentra en la llamada "Antropología Física", siendo las evidencias óseas el elemento de validación más utilizado para la construcción de modelos de poblamiento. Según este autor, Imbelloni incorpora de forma "singular y progresiva" los postulados de la escuela alemana Histórico-Cultural", donde los diferentes rasgos de las culturas contribuyen a la definición de tipos y áreas culturales y los elementos materiales permiten reconstruir la historia de los préstamos y difusión entre diferentes complejos culturales. En este marco, es posible que a Imbelloni le interesara reunir diferentes objetos y representaciones de las culturas indígenas, así como sus esqueletos y mediciones antropométricas.

${ }^{23}$ Como señala Ballestero (2013) los dibujos son considerados como un medio de expresión donde la representación gráfica no es más que el lenguaje del pensamiento. Por lo tanto, la expresión gráfica es un claro indicio del estado evolutivo de la mente del autor del dibujo. Este tipo
}

cántaros y esculturas de cera representando animales de los Toba y los Cainguá, cabellos guayaquíes y medidas antropométricas. Asimismo, asegura que conseguirá más colaboraciones para Anesi y muy probablemente más dibujos y medidas y agrega: "si hay algo más que le interesa pido instrucciones. Aquí me persigue otra vez mi mala suerte. La lluvia impide mis conferencias y todos trabajos que podría hacer para ganar plata. Ud. va entender que ya no quiero trabajar más en cualquier profesión y quisiera vivir solo para la ciencia". ${ }^{24} \mathrm{~A}$ inicios de mayo, Hanke aún no tiene noticias de la llegada de los esqueletos al museo y escribe a Imbelloni consultándole. Como en otras ocasiones, insiste -nuevamente- en su falta de recursos para continuar las exploraciones. Agrega que no ha recibido ayuda de Viena y que su "única esperanza es el Museo Argentino y Anesi", aunque antes de "pedir al Sr. Director un puesto en el Museo de Buenos Aires, quiero mandar primeramente las colecciones chaqueñas y trabajar algo más"25.

Imbelloni le reporta haber recibido en buen estado los diversos materiales enviados ${ }^{26}$, excepto los esqueletos, los cuales "podrían haber estado más completos", puesto que faltan algunas vértebras del adulto, muchos carpos y tarsos y falanges de manos y pies ${ }^{27}$. Los esqueletos, entonces, no tenían ninguna característica extraordinaria, pero esto se comprobó luego de haber sido comprados por el museo. Estas transacciones e intercambios epistolares en torno a un conjunto de objetos permiten visualizar las prácticas colectivas y heterogéneas que se vinculan con la formación de colecciones etnográficas y antropológicas. En este caso, se combinan prácticas de exploración, de escritura de textos científicos y de divulgación y actividades comerciales. Asimismo, muestra cómo el estar al tanto de las novedades científicas y mantener contactos con investigadores del museo ayudaba a la selección de piezas e información y a las formas de su compilación y transporte.

\section{Medicina, trueque, compra y otras estrategias de supervivencia}

Las prácticas de viaje, de coleccionismo y de escritura de Wanda Hanke se enmarcan en una red de relaciones

de trabajos se inserta dentro de una serie de estudios previos surgidos a lo largo del siglo XIX y principios del siglo XX como búsqueda de elementos materiales o expresiones culturales que permitieran matizar la supuesta "homogeneidad" biológica de las "razas" gracias al carácter material y simbólico de los dibujos.

${ }^{24}$ AFDME, carta de Hanke a Imbelloni, 19/04/1938

${ }^{25}$ AFDME, carta de Hanke a Imbelloni, 04/05/1938

${ }^{26}$ Los esqueletos y algunas hojas de dibujos de indios, con algunas "plásticas" en cera, pequeños objetos y una lista de medidas acompañadas por fotografías. También fueron recibidas las colaboraciones para Anesi, las cuales fueron corregidas y pasadas a máquina En esta ocasión, la tarea fue realizada por Luis Alberto Chillida y Adolfo Dembo, ambos empleados del museo que trabajaron junto a Imbelloni. Ellos, junto a Radamés Altieri e incluso el mismo Imbelloni se ocupaban de tipear y corregir los textos de Hanke.

${ }^{27}$ AFDME, carta de Imbelloni a Hanke, mayo de 1938. 
en la cual participan diferentes individuos, como los referentes de las comunidades indígenas, los encargados de las colecciones en los museos nacionales, los indígenas que venden sus vasijas o los peones que ayudan a desenterrar los esqueletos. Como se intenta mostrar en este trabajo, la conformación de las colecciones está mediada por estos sujetos provenientes de diferentes espacios y con saberes diversos; y surge de una variedad de prácticas, estrategias e intercambios, incluido el azar de hallar ciertas piezas abandonadas en el monte y el éxito o fracaso de las negociaciones mercantiles de la exploradora. El análisis de estas redes de contactos y negociaciones permite comprender las distintas posibilidades de un comerciante y explorador en el campo; como los itinerarios y la selección, traslado y organización de los objetos y la información que conforman las colecciones. Asimismo, permite dar cuenta de las diversas prácticas que subyacen a la formación de colecciones, así como reconstruir las estrategias utilizadas por un personaje con intenciones de vivir de la ciencia (no siempre muy exitosas).

En algunas ocasiones Hanke ejerció su oficio de médica en las colonias que visitaba para poder continuar con sus exploraciones. Así, en febrero de 1935, habiéndose quedado casi sin dinero y luego de recibir consejos poco favorables para viajar sola ${ }^{28}$ por el Paraguay, se dirige a Villarica y luego a Colonia Independencia (zona centro-occidental de la región del Guairá, Paraguay) "para poder ganar dinero con mi profesión de médico y continuar así mis estudios" (Hanke, 1995: 19). De la misma forma, en 1938 expresa en una de sus cartas que en la región por donde se encuentra, en los alrededores de Puerto Victoria en Paraguay, tiene "mucha ocasión para estudios científicos y podría averiguar mucho con un poco de dinero", pero si no recibe ayuda financiera tendrá que "trabajar otra vez -como los últimos mesesdando conferencias o como médica en el campo" y agrega: "nunca tenía tan mala suerte como en este

\footnotetext{
28 En su correspondencia, Hanke siempre se lamenta por "viajar sola", con todas las dificultades que implica ello para una mujer que promedia los cuarenta años. Sin embargo, estos documentos también demuestran que casi nunca está realmente sola, puesto que cuenta con ayudantes que trasladan sus bultos, peones que exhuman restos humanos y objetos arqueológicos, un secretario que traslada colecciones de Misiones a Buenos Aires y diferentes personas en las instituciones con las cuales intercambia materiales, en los puestos aduaneros en la selva o en las delegaciones diplomáticas de diferentes países; por citar algunos ejemplos. Por otra parte, Sombrio (2014) señala que, en cierta forma, los límites menos rígidos de las prácticas científicas en el campo facilitaron la incorporación de las mujeres en estas actividades. La investigación en el campo fue más difícil de reglamentar que aquella de laboratorio: "por siglos las mujeres viajaron hacia lugares distantes registrando sus observaciones en cartas, diarios y pinturas, lo cual permite la construcción de una historiografía sobre mujeres viajantes y que actuaron como investigadoras de campo." (Sombrio, 2014: 19). Sin embargo, las mujeres viajeras también tuvieron que enfrentar ciertas asociaciones entre heroísmo y masculinidad en las prácticas de campo y las dificultades de encuadrar su imagen femenina, supuestamente "destinada" al ambiente doméstico, con las condiciones adversas y los peligros que son parte de los viajes.
}

viaje"29. Asimismo, aprovechó su saber médico para dialogar e intercambiar informaciones con los curanderos nativos: "mucho interés tenían todos por la medicina. Diariamente me hacían preguntas sobre remedios, y venían enfermos, o yo los visitaba, mostrándose todos muy prudentes y obedientes. Me pidieron que yo me quedara entre ellos e instalara un consultorio y una farmacia" (Hanke, 1946: 88). En una de sus visitas a la región de los Ilamados Lenguas en el Chaco Boreal en 1939, Hanke cuenta cómo entabla muy buenas relaciones con un médico nativo y que una "vieja" de esa tribu le enseña a trabajar con diferentes yuyos para curar enfermedades. Su condición femenina le ayuda a relacionarse con las mujeres de diferentes comunidades, compartiendo algunas actividades y tareas específicas. Así sucede en su estadía con los Lenguas del Sur, en la toldería del cacique Saravia, donde la madre del cacique la acompaña al monte y le enseña cómo reconocer las hojas de caraguatá y también a preparar las fibras para los tejidos. La misma mujer le da "lecciones de hilado, tejido, alfarería y me enseñó su idioma" (Hanke, 1939). También se vinculó con algunas mujeres que vivían en las estancias, ya sean parte de la familia de los propietarios o trabajadoras indígenas; que estaban familiarizadas con el idioma indígena de la región y con los caminos y ubicación de las tolderías. Estas mujeres le facilitaron el acceso y la permanencia en distintos poblados cainguás en sus primeros años de viaje. En la medida en que fue adquiriendo experiencia y haciéndose conocida por sus exploraciones entre grupos indígenas y en territorios poco accesibles a la civilización, ejercería de "chaperona" o guía de ricas exploradoras, periodistas, investigadores o quienes estuvieran dispuestos a pagar sus servicios para internarse en el interior selvático.

El principal recurso de Hanke fue, sin dudas, la comercialización de objetos y colecciones etnográficas y antropológicas ${ }^{30}$. Los materiales que conforman las colecciones provenían de distintas personas y poblados y para obtenerlos Hanke emplea diversas estrategias, según las pautas de intercambio y las posibilidades de negociación que establece con ciertos grupos o en cada encuentro. Muchas veces intercambia objetos etnográficos mediante trueque, ofreciendo cigarrillos, géneros y prendas modernas y otros objetos occidentales. En 1939, en una carta dirigida al Director del Museo Etnográfico de la Facultad de Filosofía y Letras (Universidad de Buenos Aires), Francisco De Aparicio, Hanke manifiesta que "Para pagar la colección a los indios di casi toda mi ropa, así que Ud. ve, que yo trabajo con muchos sacrificios personales"31. En otra ocasión,

\footnotetext{
${ }^{29}$ Carta de Hanke a José Imbelloni, AFDME, 29 de enero de 1938.

${ }^{30}$ Las colecciones de Hanke que actualmente se encuentran en diversos museos han sido estudiadas en detalle por Liener (2010). Los museos que analiza esta autora son: Museum für Völkerkunde, Viena, Austria; Museum für Völkerkunde Munich, Alemania; Världskulturmuséet, Gotemburgo, Suecia; Museu de Arqueologia e Etnologia, San Pablo y Museu Paranaense, Curitiba, Brasil; Museo Etnográfico Juan B. Ambrosetti y Museo de La Plata, Argentina.

${ }^{31}$ AFDME, carta de Hanke 1/12/39
} 
cuando visita a los Sirionó en 1941, viajando por zonas cercanas a Santa Cruz de la Sierra, Hanke describe cómo obtiene algunos cráneos: "yo vi dos nenas jugando con un cráneo como una pelota y enseguida me lo vendieron por un pedazo de género. Un hombre, asistiendo a este negocio se fue a su casa y volvió con un cráneo gritando de lejos: 'aquí murió otro pariente nuestro, queremos cambiarlo por tabaco'." (Hanke 1942: 93)

En un artículo publicado en diciembre de 1937 en la Revista Geográfica Americana, Hanke relata cómo es la forma en que ha conseguido intercambiar objetos con un grupo de matacos ${ }^{32}$ residentes en una misión anglicana en el Algarrobal ${ }^{33}$. Primero ofrece cigarrillos, pero se los rechazan por las normativas de la misión, sin embargo ella insiste en ofrecerlos lejos de la mirada cristiana y consigue iniciar un intercambio:

"Se comprende que, debido a esta tendencia evidenciada por los matacos, el viajero que tiene interés en comprar algunos objetos etnográficos, encuentra muchas dificultades para realizar su propósito. El primer día, a pesar de muchos esfuerzos, no encontré más que unos cántaros y una bolsa, pero si se sabe tratar a los indios, poco a poco vienen a aparecer las fajas, los ponchos, calabazas de varios tamaños y al final pipas y juguetes. Sin embargo, pese a toda mi diligencia, no pude encontrar arma alguna (...) Una sola flecha vi en el toldo de un anciano y al preguntarle si la quería vender, éste me dijo que si y que tenía otras más (...) parece que mi "armero" había quedado contento con el precio que le pagué, ya que en los días siguientes otros llegaron ofreciéndome armas (...) también se presentaron algunas mujeres, con carreteles y una viuda anciana con un sonajero que encontró en su casa" (Hanke, 1937: 410-412).

Como se observa en la cita anterior, los objetos algunas veces se debían pagar con dinero y no con el trueque de las cosas que llevaba consigo. Para Hanke esta dependencia monetaria era un indicio de la pérdida de ciertos "valores tradicionales" de dichas culturas como en el caso de los Botocudos ${ }^{34}$ de Santa Catarina,

\footnotetext{
${ }^{32}$ Hanke señala que este grupo de matacos ha adquirido, a diferencia de otros grupos, los "rudimentos de la civilización" en gran parte debido a la misión anglicana instalada hace 20 años. Hanke pasa dos semanas allí, "observando las costumbres de la toldería india" pero encuentra muy pocos vestigios de su "propia cultura autóctona", ya que casi todos sus habitantes son cristianos y han olvidado sus mitos, sus leyendas y sus supersticiones (Hanke 1937: 409).

${ }^{33}$ La misión Ilamada "El Algarrobal" fue fundada entre los Wichí (mataco) en 1914 por los misioneros anglicanos de la South American Missionary Society. Se ubica en el chaco salteño, cerca del límite con la provincia de Formosa, Departamento de General San Martín, Municipio de Embarcación, Argentina (Gómez, 2011).

${ }^{34}$ El término "botocudo" refiere al uso del botoque (también llamado tembetá) y fue utilizado para designar a diferentes sub-grupos del grupo lingüístico Macro-Jê. Izabel Missagia de Mattos (2009) "Da etnoarqueologia à história indígena: os botocudos em seus processos
}

Brasil. Hanke contacta con este grupo en junio de 1940 y ofrece una colección de los mismos al Museo de La Plata. Junto con la lista de materiales enviados, Hanke le explica al entonces encargado del Departamento de Arqueología, el Dr. Fernando Márquez Miranda ${ }^{35}$, que "lastimosamente" los botocudos ya se olvidaron de su cultura antigua y las armas de ellos solo se consiguen por los viejos: "Los indios acá viven en un puesto del gobierno y tienen sus precios fijos en dinero. Muy poco se puede hacer con objetos de cambio como lo hice siempre en Paraguay y en el Chaco. Me permito de agregarle los precios, que yo pague en dinero, el resto compre con género nuevo"36. En una publicación sobre los Lenguas describe una situación similar: "Me recibieron y trataron muy bien, pero exigían el pago de todo lo que me proporcionaban: ni el agua me daban gratis". Por estos motivos, para Hanke los Lenguas del Sur tienen mucha "degeneración", y cree que es "evidente que el contacto con los blancos contribuye a corromper a los indígenas"37 (Hanke, 1939).

Por otra parte, algunos de los materiales que conforman las colecciones de Hanke son obtenidos de campamentos abandonados o de lugares "dispersos en el monte". Como se mencionó arriba, en $1935^{38}$ Hanke envía una caja con materiales obtenidos de los Guayaquíes y los Cainguás al Museo Argentino de Ciencias Naturales "Bernardino Rivadavia", remitiendo también en sus bultos una caja con insectos y muestras de alfarería. La procedencia de los objetos es diversa, algunos son obtenidos por intercambio en las tolderías, otros son recolectados en un campamento abandonado, unas agujas son tomadas de una mujer "escapando de nosotros, en el monte, a siete leguas de Ñuverá" y otros son regalados a Hanke por dos mujeres, con las cuales ella dice "tener relación"39. Estos objetos de diversa procedencia son reunidos y organizados en calidad de "colecciones". Las mismas contienen informaciones adicionales, como la descripción del uso de los objetos, justificando de alguna manera su pertenencia a la colección, como por ejemplo unas "piedras para abrir frutas". No queda claro en los documentos de Hanke si los usos asignados a los objetos recolectados son registrados a partir de lo relatado por

identitários (século xix ao xxi)", en: Habitus, v. 7, n 1.2, pp: 75-97.

35 Fernando Márquez Miranda (1897-1961) fue un antropólogo argentino que trabajó sobre diferentes temas de arqueología y etnología de poblaciones indígenas. De forma discontinua, se desempeñó en diferentes instituciones como la Facultad de Filosofía y Letras de la Universidad de Buenos Aires y la Facultad de Humanidades y Ciencias de la Educación y el Instituto del Museo/Facultad de Ciencias Naturales de la Universidad Nacional de La Plata (Soprano, 2014).

${ }^{36}$ AHMLP, carta de Hanke 13/08/1940

37 Es interesante señalar al respecto que jamás menciona las consecuencias de sus propias acciones, en tanto "blanca", visitando las comunidades y comprando mediante trueque o dinero los objetos o pidiendo que se los fabriquen.

38 Carta de Hanke a Doello Jurado, AFDME, 9/sept/1935

39 Dicha relación es relatada en la nota publicada por Hanke en La Prensa en 1936. En la misma se cuenta cómo contactan ella y su ayudante paraguayo con un pequeño grupo de guayaquíes, un joven y algunas mujeres, intercambiando objetos y compartiendo algunas experiencias en el monte. 
los informantes o vendedores de los objetos, o por sus propias observaciones.

Las distintas formas de recopilar, describir y organizar los materiales permiten comprender ciertas prácticas ligadas al coleccionismo hacia mediados de siglo XX, mostrando el carácter colectivo que subyace a las mismas. Como se ha analizado en diferentes trabajos, la comprensión de las actividades ligadas al coleccionismo remite a diferentes aspectos culturales de la práctica científica y a la influencia del papel de los mediadores e intermediarios y sus efectos en la producción de conocimiento (Kuklick y Kohler, 1996). También remite al carácter transaccional de la ciencia (Podgorny, 2013) y a las instancias de intermediación en la formación de colecciones; donde los informantes y proveedores de objetos en el "campo" tienen un papel activo en la selección de los materiales que conformarán esos conjuntos de objetos etnográficos, incorporadas luego en los museos como las representaciones materiales de los grupos indígenas. Los procesos de adquisición, exposición y catalogación de estos objetos, integrados luego a otros conjuntos para conformar representaciones materiales de las culturas, terminan muchas veces ocultando los diferentes procesos y agentes que participaron en la creación de las colecciones.

\section{Recopilación lingüística y de otras informaciones etnográficas}

Junto con los objetos que conforman las colecciones, como se dijo, Hanke envía otras informaciones reunidas en sus exploraciones, entre ellos los mitos y creencias vinculados a estos elementos o sus usos y funciones en la vida cotidiana de los indígenas. Asimismo, complementa las descripciones con fotografías de los sitios donde se excavó o de los nativos en su estado "natural", con dibujos que copian representaciones sobre la cerámica y diversos utensilios, tatuajes y otros símbolos (ver imagen 1). Con el paso del tiempo incluirá también descripciones y relevamientos lingüísticos de los diferentes grupos con los cuales establece contacto. Como señala Farro (2013) las recopilaciones lingüísticas de diferentes grupos contribuyeron con el desarrollo de la antropología, de la historia y de la geografía en la Argentina; siendo la clasificación de las lenguas uno de los "hilos de Ariadna" que posibilitaron internarse en el laberinto de los grupos indígenas del pasado y sus sucesivos desplazamientos geográficos.

Estas "transcripciones" más de una vez le generaron problemas a Hanke en relación a su manejo del idioma español. Dichos problemas también se traducen en términos de adquisición de los objetos y de otras informaciones que los acompañan, puesto que sus dificultades ponen en duda también su "pericia" como recolectora de campo. Así sucede con los materiales de los Botocudos que envía al Museo de La Plata en
1940. Como es común en la época, la carta de la exploradora ofreciendo las colecciones -y su precio de venta- llega antes que los materiales. Sin las colecciones en mano (o por causa de ello), el jefe de la Sección de Etnografía y Arqueología, Márquez Miranda no podía informar al Director del Museo, sobre el "valor venal" e interés de esos objetos para la sección. Por otra parte, el ofrecimiento no era claro en cuanto al dinero invertido en estas colecciones: "pues su carta -escrita en un español aproximativo- no es muy clara, ya que unas veces se refiere a valores en dinero y otras a mero canje en tejidos de confección occidental"40.

El recurso al trueque empleado por Hanke, hacía que fuera difícil establecer el monto a pagar por cada pieza. Además, su "español aproximativo" constituía un problema en relación a la información recolectada por Hanke, como unos "cantos antiguos" de los botocudos y algunos apuntes gramaticales que remite a La Plata. Al respecto, Márquez Miranda ${ }^{41}$ señala que "su ya citado poco conocimiento de nuestro propio idioma y de la cultura de los indígenas que visita, reducen considerablemente las posibilidades de haber realizado una labor susceptible de utilización directa". ${ }^{42}$

Las recopilaciones lingüísticas, así como otros objetos que recolectaba Hanke, son entendidas en este trabajo como un conjunto de materiales heterogéneos, obtenidos mediante diferentes procesos y estrategias. Con ello, se intenta aportar al estudio de los procesos de formación de las colecciones etnográficas, las cuales -como se muestra con diferentes ejemplos- son muchas veces definidas y organizadas en función de situaciones contingentes o azarosas que suelen depender de la negociación de múltiples voluntades.

\section{Consideraciones finales}

Como se intentó mostrar a través de algunos ejemplos, las negociaciones alrededor de las colecciones antropológicas muestran algunas disputas y conflictos e ilustran cómo las mismas son definidas en relación a intereses diversos. Como se señaló al principio, esta combinación de prácticas científicas y comerciales no es una excepción en Hanke, sino que ha sido analizada en diferentes trabajos que se dedican a la historia de las colecciones y de los museos argentinos (Pegoraro, 2003, 2009; García, 2007; Lindskoug, 2008; Podgorny

\footnotetext{
40 AHMLP, nota de Márquez Miranda a la Dirección del Museo, $5 / 10 / 1940$

${ }^{41}$ Op. Cit.

42 A fines de octubre de 1940 llega la colección de los botocudos al Museo de La Plata, los mismos comprenden arcos, flechas, lanzas, canastos de diverso tamaño, fajas tejidas de fibras vegetales, entre otros. Márquez Miranda considera que el material es interesante y acuerda con el precio que Hanke pidió por ellos. Unos meses después, esta colección será utilizada para renovar la Sala de Etnografía del Museo. Los materiales son catalogados por Marquez Miranda como pertenecientes a los Bororós. AHMLP, nota de Marquez Miranda a la Dirección, 2/06/1941
} 
y Lopes, 2008; Farro, 2009; Pupio, 2011; Bonnin 2011; Martínez, Taboada y Auat, 2011; Pupio y Piantoni 2016). Las prácticas realizadas por Hanke y otros coleccionistas y personajes de la época también pueden ser leídas en el marco de la historia de las "ciencias del terreno", una línea de investigación donde el "trabajo de campo" se define como una actividad práctica compleja, de naturaleza colectiva y que exige la cooperación de un grupo socialmente diverso de practicantes -estudiosos, directores de las instituciones científicas, residentes locales, personal de las reparticiones estatales, entre otros- quienes atribuyen distintos significados tanto a los objetos recolectados como a las tareas llevadas a cabo en el terreno (Farro, 2009).

Por otra parte, varios trabajos señalan que en la década de 1930 se asiste a ciertos cambios a nivel institucional en las ciencias antropológicas en la Argentina y se reconocen en estos años los primeros indicios de su profesionalización (Perazzi, 2003; Podgorny, 2002, 2004b; Martínez, Taboada y Auat, 2011). Asimismo, se han analizado las tensiones y debates entre el proceso de construcción de una antropología "como disciplina académica" y como una "ciencia aplicada" hacia mediados de siglo XX (Lazzari, 2004). Sin embargo, los documentos analizados en este trabajo muestran la heterogeneidad de las prácticas científicas antropológicas en estos años, así como la participación de personajes amateurs, coleccionistas, comerciantes de objetos científicos, exploradores, entre otros. Si bien se ha analizado el papel que cumplen estos individuos en la historia de la ciencia, pocos trabajos se han detenido a examinar las formas en que las prácticas de esos personajes perduran en la Argentina del siglo XX.

La actuación de Hanke pone en jaque las distinciones entre profesionales y amateurs, mostrando la existencia de prácticas y trayectorias que se mueven en los límites no bien definidos del quehacer científico. Sus prácticas se asemejan a las de otros personajes de la época, pero son difíciles de definir. Esta exploradora intenta conseguir puestos estables en diferentes instituciones pero no lo consigue, a diferencia de otros casos como los mencionados del alemán von Hauenschild o de los hermanos Wagner. Los objetos y otras informaciones que obtiene Hanke son agrupados y vendidos a diferentes museos, en ningún momento se dedica a la formación de una colección personal, tampoco cuenta con un lugar de vivienda permanente. En ese sentido, el caso de Hanke se puede comparar con aquellos personajes itinerantes que desde el siglo XIX recorrieron el continente sudamericano adoptando la identidad de explorador, pero también desarrollando prácticas ligadas a la medicina, el periodismo y el mercado del coleccionismo (Podgorny, 2008, 2010 2011). De esta forma, estos individuos, circulando por mundo diferentes, articularon actividades científicas y mercantiles alrededor del conocimiento y de los objetos de pueblos indígenas. Como señala Podgorny (2011) el estudio de este tipo de personajes descartados $u$ olvidados en ciertos relatos de la historia de la ciencia, posibilita mostrar el lado colectivo e híbrido de la ciencia y de la producción del conocimiento.

El conocimiento, desde esta perspectiva, aparece como algo que se modela en el intercambio y la circulación de objetos, ideas y personas, pero también en las estrategias para construir una "autoridad científica" y conseguir un empleo o recursos para sobrevivir y seguir viaje.

La Plata, 11 de octubre de 2016

\section{Agradecimientos}

Este artículo fue posible gracias a mi beca doctoral que financia la Universidad de La Plata, a las instituciones que permitieron el acceso a su documentación y a las personas que facilitaron dicha consulta; especialmente agradezco a Marisa Scarafoni del Archivo Fotográfico y Documental del Museo Etnográfico, a Diego Gobbo y Mariano Bonomo de la División Arqueología del Museo de La Plata y a Maximiliano Farro del Archivo Histórico del Museo de La Plata. También agradezco a Susana García por la paciente lectura de los borradores de este trabajo.

\section{Bibliografia}

Ballestero, D. A. (2013). Los espacios de la antropología en la obra de Robert Lehmann-Nitsche, 1894-1938 (Tesis doctoral). Facultad de Ciencias Naturales y Museo, Universidad Nacional de La Plata, Argentina.

Carrizo, S. 2014. Puntos, líneas y rombos proyectados en el biosólido craneal: los inicios de la trayectoria académica de José Imbelloni en la antropología argentina. En Guber, Rosana (comp.) Antropologías argentinas. Determinaciones, creatividad y disciplinamiento en el estudio nativo de la alteridad. (pp. 43-86). La Plata: Ediciones al Margen.

Farro, M. (2009). La formación del Museo de La Plata. Coleccionistas, comerciantes, estudiosos y naturalistas viajeros a fines del siglo XIX. Rosario: Prohistoria ediciones.

Farro, M. (2013). Observadores de gabinete, lenguas indígenas y "tecnología de papel": El archivo de trabajo de Samuel A. Lafone Quevedo. Ponencia presentada en VI Jornadas de Filología y Lingüística, La Plata, Argentina.

García, S. (2007). Museos escolares, colecciones y la enseñanza elemental de las ciencias naturales en la Argentina de fines del siglo XIX. História, Ciências, Saúde-Manguinhos, vol. 14, n²1, pp. 173-196. 
García, S. (2011). Museos provinciales y redes de intercambio en la argentina. En Lopes, M. M. y Heizer, A. (comp.) Colecionismos, práticas de campo $e$ representações. (pp. 77- 94). Campina Grande: EDUEPB.

Gómez, M. D. (2011). ¿Morirán mis hijos o las frutas del monte se secarán si no canto y uso mi amuleto cada noche? Mujeres tobas (qom) y Misioneros Anglicanos en el Chaco Centro occidental (Argentina). Cadernos Pagu (36), pp. 187-222.

Grupioni, L. D. B. (1998). Coleções e Expedições Vigiadas: Os Etnólogos no Conselho de Fiscalização das Expedições Artísticas e Científicas no Brasil. San Pablo: Hucitec/Anpocs.

Hanke, W. (1936). Los primeros guayaquíes. En: La Prensa, 1 de marzo.

Hanke, W. (1937). Una excursión entre los indios matacos. Revista Geográfica Americana, año V, VOL VIII, n 51, pp. 409-415.

Hanke, W. (1938). Los indios Guayaquí. Revista Geográfica Americana, año V, VOL X, n 59, pp. 117122.

Hanke, W. (1939). Jira por la región de los indios lenguas. Revista Geográfica Americana, año VI, VOL XI, n 69, pp. 441-445

Hanke, W. (1942). Los indios Sirionó de la Bolivia Oriental. Arquivos do Museu Paranaense. Vol II, julio, pp. 87-96.

Hanke, W. (1946). Sierras y ciudades del sud de Brasil. Revista Geográfica Americana, año XIII, VOL XXVI, $\mathrm{n}^{\circ}$ 155, pp. 81-90.

Hanke, W. (1995). Dos años entre los Cainguá. Buenos Aires: Centro Argentino de Etnología Americana.

Kuklick, H. y R. Kohler. (1996). Introduction. Osiris, Vol. 11, Science in the Field, pp 1-14.

Lazzari, A. (2004). Antropología en el Estado: el Instituto Étnico Nacional (1946-1955). En Neiburg, F. y Plotkin, M. (comps.) Intelectuales y expertos. La constitución del conocimiento social en la Argentina. (pp. 203-230). Buenos Aires: Paidós.

Liener, S. M. (2010). Wanda Hanke (1893 - 1958). Eine österreichische Ethnologin in Südamerika (Tesis de maestría). Universidad de Viena, Alemania.

Sombrio Moraes de Oliveira, M. y M. M. Lopes. (2011). Wanda Hanke e a formação de coleções etnográficas na América do Sul. Ponencia presentada en Anais do XXVI
Simpósio Nacional de História - ANPUH, São Paulo.

Martínez, A. (2012). Fotografía y hechos científicos. Los guayaquíes y las discusiones de la antropología a fines del siglo XIX. En Kelly, T e I. Podgorny (Dir.) LoS secretos de Barba Azul, Fantasías y realidades de los archivos del Museo de La Plata. (pp 105-138). Rosario: Prohistoria Ediciones.

Ocampo Moscoso, E. (1982). Wanda Hanke en la etnografía boliviana. La Paz: Juventud.

Pegoraro, A. (2003). Estrategias de formación de colecciones del Museo Etnográfico durante el período 1904-1917. Funcionarios de gobierno en la recolección de piezas. En Lorenzano, C. (ed.), Historias de la Ciencia Argentina I. (pp. 17-28). Buenos Aires: EDUNTREF.

Pegoraro, A. (2009). Las colecciones del Museo Etnográfico de la Universidad de Buenos Aires: un episodio en la historia del americanismo en la Argentina 1890-1927 (Tesis de doctorado). Facultad de Filosofía y Letras, Universidad Nacional de Buenos Aires, Argentina.

Penny, G. H. (2002). Objects of Culture. Ethnology and Etnographic Museums in Imperial Germany. Chapel Hill and London: The University of North Carolina Press.

Perazzi, P. (2003). Antropología y Nación: materiales para una historia profesional de la Antropología en Buenos Aires. Runa. Archivo para las ciencias del hombre, $\mathrm{N}^{\circ}$ 24, pp. 83-102.

Podgorny, I. (2002). Ser todo y no ser nada: paleontología y trabajo de campo en la Patagonia argentina a fines del siglo XIX. En Visacovsky, S. y R. Guber (comps.) Historia y estilos de trabajo de campo en Argentina. (pp. 31-77). Buenos Aires: Antropofagia.

Podgorny, I. (2004b). Tocar para creer. La arqueología en la Argentina, 1910-1940. Anales del Museo de América, n. 12 , pp. 147-163.

Podgorny, I. (2008). Momias que hablan. Ciencia, colección de cuerpos y experiencias con la vida y la muerte en la década de 1880. Prismas, Revista de Historia Intelectual. Número 12. pp. 49-65.

Podgorny, I. (2010) Coleccionistas de arena. La comisión médico-quirúrgica italiana en el altiplano boliviano (1875-1877). Antípoda. Número 11, julio-diciembre. pp. 165-188.

Podgorny, I. (2011). Los viajes en Bolivia de la Comisión Científica Médico-Quirúrgica Italiana. Santa Cruz: Fundación Nova.

Podgorny, I. (2013). La febbre dei fossili Pedro de Angelis 
y el carácter transaccional de la ciencia. Zama. Revista del Instituto de Literatura Hispanoamericana, año 5, número 5, pp. 11-216.

Podgorny, I. y M. Lopes. (2008). El desierto en una vitrina. Museos e historia natural en la Argentina, 1810-1890. México: Limusa.

Podgorny, I. y M. M. Lopes. (2013). Trayectorias y desafíos de la historiografía de los museos de historia natural en América Del Sur. Anais do Museu Paulista. V.21. n.1. pp. 15-25.

Pupio, A. (2011). Coleccionistas, aficionados y arqueólogos en la conformación de las colecciones arqueológicas del Museo de La Plata, Argentina (1930-1950). En Lopes, M. M. y Heizer, A. (comp.) Colecionismos, práticas de campo e representações. (pp. 269-280). Campina Grande: EDUEPB.

Pupio, A. y Piantoni, G. (2016) Coleccionismo, museo y saberes estatales. La colección de Enrique Amadeo Artayeta en el Museo de la Patagonia (Argentina)1939-1950. Estudios Sociales del Estado, volumen 3, número 5, pp. 31 a 54.

Sombrio, M. (2014). Em busca pelo campo: ciências, coleções, gênero e outras histórias sobre mulheres viajantes no brasil em meados do século XX (Tesis doctoral). UNICAMP, Brasil.

Soprano, G. (2014). Lecturas, interpretaciones y usos de la "Escuela Histórico-Cultural" en la producción arqueológica y etnográfica de Fernando Marquez Miranda. En Guber, Rosana (comp.) Antropologías argentinas. Determinaciones, creatividad $y$ disciplinamiento en el estudio nativo de la alteridad. (87-128). La Plata: Ediciones al Margen.

Vellard, A-J.(1933). Una misión de estudios al Paraguay. Revista Humanidades, Tomo XXIII, pp. 83-103.

Zusman, P. (2012). La Revista Geográfica Americana en la década de 1939: entre el modelo de la National Geographic y la invención de los paisajes argentinos orientados a la práctica turística. Registros, Mar del Plata, año 8 (n.9): 81-96. 